physical evidence, sometimes at variance, is assessed separately). Such an approach, as admitted by the editors, results in a degree of repetition and an overlap of material in some instances. However, it is useful and interesting to see the physical and historical evidence summarized independently.

Another difficulty which the investigators faced, because of the paramount consideration for the safety of the royal mummies, was the necessity of examining the mummies in their modern wooden cases in the museum, instead of under near-ideal conditions in a modern radiology department where sophisticated equipment and a variety of radiological techniques would have been available. There is a consequent lack of quality in the $\mathrm{X}$-rays and possibly in the completeness of the evidence obtained.

However, some of the most interesting results included the observation that, unlike certain other Egyptian mummy collections, these royal mummies showed a marked degree of cultural and genetic heterogeneity. This reflected the presence of foreign princes and princesses in the Egyptian royal family of the New Kingdom rather than the averred custom of royal consanguineous marriages undertaken to ensure succession to the throne. Another tentative conclusion, reached through the use of scienctific techniques, was that a mummy known previously as the "Elder Lady" was in fact probably Queen Tiye, a close relative of Tutankhamun.

Nevertheless, the caution which historians should observe in utilizing the results of such scientific investigations is well illustrated by one of the conclusions drawn here. This concerns the proposed relationship between the pharaohs Amenhotep III and Tutankhamun. Previous investigations of the mummies attributed to these kings, undertaken by Professor R. G. Harrison and his colleagues, and based on palaeoserological and anatomical observations, had indicated that Amenhotep III was probably Tutankhamun's father. However, a different conclusion is drawn here: "The cephalometric X-ray records would not support the ... contention. It is most improbable that the mummy designated Amenhotep III was the biologic father of King Tutankhamun'.

The second book reviewed here, Mummies, Disease and Ancient Cultures, deals with a wider range of techniques and also shows how a variety of societies have preserved their dead, either unintentionally or by artificial methods, as "mummies". This study again shows the value of a multidisciplinary approach. In the long term, it is hoped that the work will go some way towards answering questions concerned with the origin of diseases and their evolution in different societies. To this end, the team is committed to a detailed pathological study of world-wide collections of mummies.
A summary is given of the work to date, and although Egyptian and South American mummies have received most detailed attention at present, a survey of other mummified remains is included those discovered in the United States, the Aleutian Islands, Alaska, the bog bodies of Denmark, mummies in Australia and Melanesia, and Japanese examples.

A complete section is devoted to reports of the techniques involved in this study which include physical anthropology, radiology, histology, electron microscopy, palaeoserology and palaeobiochemistry. Not only does the book illustrate the various methods - heat-drying, freezing or the application of dehydrating agents - by which a body can be preserved, but it also shows how diverse are the religious and environmental reasons which bring about mummification in different parts of the world.

Both books reflect a resurgent interest in the application of scientific techniques to the physical remains of ancient societies, which, used with due caution and appreciation of the possible fallability and limitations of such investigations, can provide the historian with a valuable additional insight.

Rosalie David is the Egyptologist at the Manchester Museum, University of Manchester, and Director of the Manchester Egyptian Mummv Research Project.

\title{
The cradle of geology refurbished
}

\section{John Sutton}

The Geology of Europe. By Derek V. Ager. Pp.560. ISBN 0-7084-115-2. (McGrawHill: 1980.) £16, \$38.40.

IN MY opinion this is much the best account of the geology of Europe to have appeared since Gignoux published his Géologie Stratigraphique over 50 years ago. Derek Ager describes his subject as Europe seen by a stratigrapher-palaeontologist. $\mathrm{He}$ treats his material very differently from Gignoux and the contrast is illuminating. Gignoux drew nine-tenths of his examples from Europe, and, in so doing, produced a comprehensive account of its geology which started with the oldest rocks, proceeded through younger formations to the most recent, providing abundant stratigraphical successions and the like on the way. Ager throws this approach out of the window; there is hardly a stratigraphical table in the book, so that he has space for much else.

Ager divides Europe into four regions on the basis of the relative ages of the last extensive period of metamorphism and deformation to have affected them. The geological history of each region is then described from start to finish - a method which brings out relations of older and younger events particularly well. Each of the four sections ends with a concluding chapter a few pages long. I was particularly struck with Ager's concise, five-page summary of Precambrian Europe. Although, as he puts it, "the Precambrian history of our continent is for the most part lost in the mists of metamorphism', he packs a telling account into that brief chapter.

The main virtue of this book is the way in which it brings together details to give a geological picture on a continental scale. Derek Ager has an interesting approach to geophysics; he appreciates "the hurricane of fresh air that new geophysical thoughts breathed into our subject". He goes on to write what is one of the best accounts of any continent, set out on precisely the scale which would make it possible to compare the geological history of basins and uplifted crystalline blocks with the results of geophysical surveys. Such comparison, however, he leaves to others. He gives a good defence of his treatment, and in his introduction makes the point that any additional matter has to be balanced by the omission of something else. However, in a second edition I would hope at least to see a discussion of outline gravity and magnetic maps, and an account of crustal thickness.

Of all the continents, Europe is probably the most difficult to handle. Its geology is discussed in 20 languages, it is criss-crossed by frontiers and its complexities are probably the most apparent of any continent. Ager sails through all these difficulties triumphantly. He has travelled the continent repeatedly, he lists friends and helpers in every country; he is bold in his summaries and he writes with great clarity, and is not afraid to say what he thinks is important. Personal touches abound; we hear about the view from his study window and the nature of the rock surmounting the Ager garden gate. Historical figures pop up from time to time: Drake's game of bowls and the sailing of the Pilgrim Fathers illuminate the account of Plymouth Hoe. Whether, in consequence, one remembers which stage of the Devonian outcrops below the turf is probably a matter of individual experience. I expect every reader will find some of the allusions obscure; there are plenty of traps for the translators who will certainly get to grips with this most useful book. Unless they know their Sherlock Holmes and Irish mythology, we may yet see chien de chasse des Basquervilles and Blarneystein among the faunal lists and formation names of the future.

John Sutton is Pro Rector and Professor of Geology at Imperial College, University of London. 